8-1-2019

\title{
Conocimiento, actitudes y prácticas sobre el zika: implicancias programaticas para la prevencion del Zika en Honduras
}

Breakthrough RESEARCH

Follow this and additional works at: https://knowledgecommons.popcouncil.org/departments_sbsr-pgy

Part of the Health Communication Commons, and the Public Health Commons How does access to this work benefit you? Let us know!

\section{Recommended Citation}

Breakthrough RESEARCH. 2019. "Conocimiento, actitudes y prácticas sobre el zika: implicancias programaticas para la prevencion del Zika en Honduras," Programmatic Research Brief. Washington, DC: Population Council. 


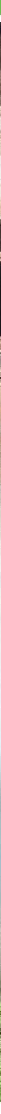

Conocimiento, actitudes

y prácticas sobre el Zika

IMPLICANCIAS PROGRAMÁTICAS PARA LA PREVENCIÓN DEL ZIKA EN HONDURAS

Este informe ofrece algunas conclusiones importantes para ejecutores de actividades de cambio social y de comportamiento para la prevención del Zika en Honduras. Esta información está basada en datos de una muestra representativa de personas que viven en comunidades que forman parte del programa de Respuesta al Zika de la Agencia para el Desarrollo Internacional de los Estados Unidos (The United States Agency for International Development-USAID). Estos datos sirven como una aproximación empírica, basada en evidencia, para desarrollar programas que aumenten los comportamientos preventivos del Zika y de otras enfermedades transmitidas mediante el Aedes aegypti. Nuestros resultados indican que se necesita: (1) reducir las brechas de información y la desinformación que existe sobre el virus del Zika, particularmente respecto a sus efectos adversos sobre la salud y prácticas de prevención efectivas; e (2) informar detalladamente sobre comportamientos preventivos para que sean llevados a cabo de manera efectiva por parte de la población. 


\section{Antecedentes}

El primer brote de Zika registrado en las Américas ocurrió en 2015, cuando hubo una alza en malformaciones congénitas y otras complicaciones neurológicas. ${ }^{1}$ En abril del 2016, el Departamento de Estado de los Estados Unidos destinó fondos para una Respuesta al Zika de la USAID, priorizando, en países afectados, esfuerzos programáticos orientados a minimizar los efectos negativos del Zika durante el embarazo.

Un elemento central de la Respuesta al Zika de la USAID son los programas de cambios sociales y de comportamiento, que tienen como objetivo promover prácticas y comportamientos efectivos que reduzcan la transmisión del Zika. Estos programas enfatizan la protección personal para mujeres embarazadas, involucran a comunidades de alto riesgo en prácticas de prevención, y mejoran el acceso de mujeres a servicios de atención prenatal.*

\section{¿Por qué levantamos información sobre conocimiento, actitudes y prácticas?}

Las teorías de cambio de comportamiento nos ayudan a entender qué factores facilitan y motivan a las personas a comportarse de una manera u otra. ${ }^{4} \mathrm{El}$ modelo socioecológico de cambio de comportamiento destaca la importancia de factores individuales (como el conocimiento, las percepciones y las actitudes sobre una enfermedad y su prevención), factores comunitarios (como el ambiente normativo) y factores sociales y estructurales (como el acceso a recursos y servicios) para entender si una persona realiza o no un comportamiento en particular. Otro modelo-Extended Parallel Processing Model-destaca que la percepción de riesgo que una persona asocia con una enfermedad, como también su confianza en la efectividad de una posible solución y su compromiso con practicarlas, impactará en que una persona realice prácticas preventivas o no. ${ }^{4}$ Esta y otras teorías ofrecen una base para medir indicadores que permiten que ejecutores de programas de cambio social y de comportamiento decidan las mejores estrategias para impactar el comportamiento de comunidades específicas.

\section{¿Cómo se recopilaron los datos?}

En el año 2018, el proyecto Breakthrough RESEARCH realizó una encuesta transversal de hogares en Guatemala, Honduras, El Salvador y la República Dominicana. La encuesta evaluó, entre otros factores, el conocimiento, las actitudes y los comportamientos (CAP) relacionados al Zika y a otras enfermedades transmitidas por el mosquito Aedes aegypti. Se utilizó un diseño muestral aleatorio, multietápico y por conglomerado. Se encuestaron hombres y mujeres de entre 18

\footnotetext{
* Para mayor información visite:

www.usaid.gov/what-we-do/global-health/zika.
}

\section{¿POR QUÉ IMPORTA EL ZIKA?}

- El virus del Zika es una enfermedad contagiosa transmitida por los mosquitos Aedes aegypti, que también transmiten otros arbovirus, como el dengue y la chikunguña.

- El Zika también se puede transmitir a través de relaciones sexuales y de una madre embarazada a su feto.' Se sabe que el Zika puede causar problemas neurológicos, como el síndrome congénito por el virus del Zika. ${ }^{2,3}$

- Muchas personas infectadas con el virus del Zika no desarrollan síntomas, lo que genera una percepción de riesgo menor. ${ }^{2}$

y 49 años, residentes de áreas de intervención de programas de la USAID. En Honduras, la encuesta fue realizada entre agosto y octubre del 2018 en las áreas de intervención del programa de respuesta al Zika de la USAID de cinco provincias: Francisco Morazán, Olancho, Valle, Choluteca, y El Paraíso. 609 individuos fueron entrevistados, de los cuáles 36 por ciento eran hombres y 64 por ciento eran mujeres. Los datos se ponderaron según características sociodemográficas a modo de reflejar la población de las áreas de intervención.

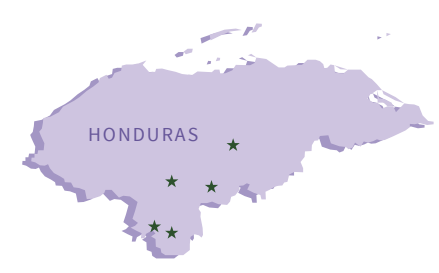

El estudio recogió información sobre cuatro grandes dimensiones:

- Información sociodemográfica: Edad, educación, sexo, bienes del hogar.

- Conocimiento: Transmisión, efectos en la salud, prevención de cada enfermedad.

- Actitudes: Percepciones de riesgo de la enfermedad, efectividad de comportamientos preventivos, factibilidad de llevar a cabo conductas preventivas.

- Autorreporte de conductas preventivas: Comportamientos para prevenir picaduras de mosquitos y criaderos de mosquitos en los últimos siete días y en los últimos treinta días.

- Prácticas observadas: Identificación del uso de tapas seguras para el almacenamiento de agua donde suelen estar los criaderos de mosquitos. 


\section{Implicancias programáticas claves}

Estas recomendaciones para programas que impulsen cambios sociales y de comportamiento están basadas en hallazgos de las encuestas realizadas en Honduras.

1. Los mensajes de prevención debiesen continuar destacando el rol de la transmisión sexual del Zika, especialmente entre mujeres embarazadas y sus parejas, y enfatizar la importancia del condón para evitar la transmisión del virus durante el embarazo.

2. Los programas y mensajes de prevención debiesen destacar los vínculos entre el virus del Zika y posibles defectos congénitos, incluyendo el síndrome congénito por el virus del Zika, especialmente entre la población masculina. Esto distingue al Zika de otros arbovirus. Para mujeres embarazadas y sus parejas, tener un hijo saludable puede ser una motivación fundamental para prevenir el virus.

3. Los programas de prevención debiesen priorizar comportamientos que cuentan con evidencia de su efectividad contra las enfermedades transmitidas por el Aedes-aegypti; y los mensajes debiesen destacar esta evidencia.

4. Los programas de prevención debiesen incluir mensajes que contengan instrucciones detalladas para realizar comportamientos preventivos complejos.

5. Los mensajes de prevención entregados durante visitas domiciliares de control vectorial son una estrategia prometedora para aumentar el conocimiento de las personas y promover conductas preventivas.

\section{Hallazgos clave sobre el conocimiento del Zika}

\section{Conocimiento de la enfermedad}

La gran mayoría de las personas encuestadas había escuchado del Zika, dengue o chikunguña, y 90 por ciento de las personas había escuchado sobre las tres enfermedades (ver Tabla 1).

\begin{tabular}{|c|c|}
\hline ENFERMEDAD & $\begin{array}{c}\text { \% DE PERSONAS QUE HAN } \\
\text { ESCUCHADO DE LA ENFERMEDAD }\end{array}$ \\
\hline Zika & $99 \%$ \\
\hline Dengue & $95 \%$ \\
\hline Chikunguña & $91 \%$ \\
\hline
\end{tabular}

Mecanismos de transmisión del Zika y sus efectos en la salud

Mediante mosquitos: Entre quienes respondieron conocer cada enfermedad, casi todos estaban informados de que los mosquitos pueden transmitir Zika (92 por ciento), dengue (98 por ciento) y chikunguña (95 por ciento). Casi dos tercios de quienes sabían que estas tres enfermedades se transmiten mediante mosquitos sabían que una picadura puede ocurrir a cualquier hora del día o de la noche (66 por ciento, 68 por ciento y 68 por ciento, respectivamente).

Mediante contacto sexual y transmisión vertical: Solo 11 por ciento de los encuestados que había escuchado del Zika sabía que se puede transmitir sexualmente y solo 3 por ciento sabía que se puede transmitir de una madre a un feto durante el embarazo.

Solo 33 por ciento de los encuestados que había escuchado del Zika identificó defectos congénitos como un posible efecto adverso del Zika sobre la salud. Mientras un 39 por ciento de las mujeres estaba al tanto que los defectos congénitos son un posible efecto del Zika, solo un 27 por ciento de los hombres sabían $(p<0.01)^{+}$

+ Se utilizó la prueba de chi-cuadrado para todos los análisis bivariados. 


\section{Métodos de prevención}

De los participantes que habían escuchado sobre el Zika, un 92 por ciento conocía al menos un método efectivo para prevenir el virus..$^{\ddagger}$

El método de prevención más conocido para reducir el riesgo del Zika fue vaciar agua estancada ( 65 por ciento), quitar basura cercana a la vivienda que alberga mosquitos (deschatarrización) (66 por ciento), y limpiar recipientes o contenedores de agua (60 por ciento).

Solo 25 por ciento de los participantes identificó que tapar recipientes de agua y solo 17 por ciento identificó el uso de larvicida como métodos de prevención. Asimismo, 11 por ciento identificó el uso de repelentes y tres por ciento identificó el uso de condones como métodos de prevención.

\section{Hallazgos claves de actitudes sobre el Zika}

\section{Percepciones de riesgo del Zika, dengue y chikunguña}

Como muestra la Figura 1, aproximadamente la mitad de los participantes percibe estar en una situación de poco riesgo o fuera de riesgo de contraer Zika, dengue o chikunguña (51 por ciento, 49 por ciento y 50 por ciento, respectivamente). La percepción de riesgo del Zika estaba correlacionada al nivel de riqueza: 37 por ciento del quintil más pobre percibe estar a un nivel alto de riesgo, mientras solo 12 por ciento del quintil más rico percibía lo mismo $(p<0.001)$.

\section{FIGURA 1. PERCEPCIÓN DE RIESGO POR ENFERMEDAD}

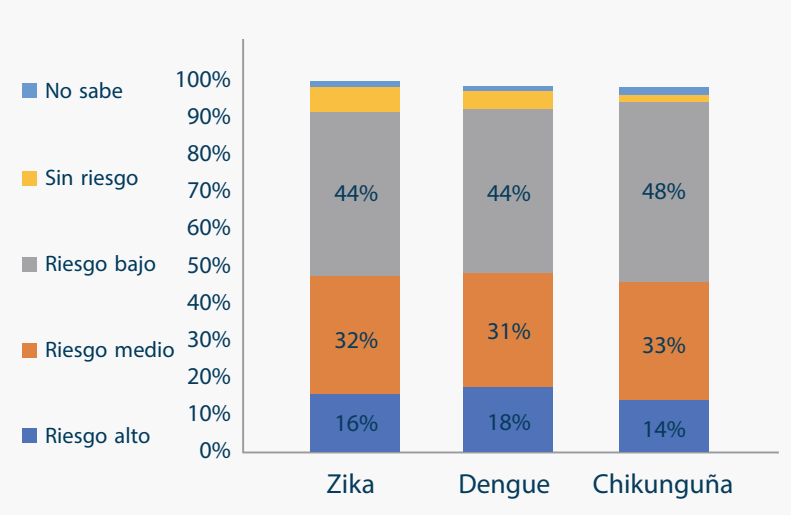

‡ Comportamientos efectivos: Usar repelente, vaciar agua estancada, limpiar recipientes y contenedores de agua, tapar recipientes y contenedores de agua, usar larvicida, usar rejillas en ventanas y puertas.

\section{Percepciones de factibilidad de conductas preventivas}

Al responder sobre cómo perciben la factibilidad de las conductas preventivas incluidas en la Tabla 2, ninguna de las alternativas fue considerada como muy fácil de llevar a cabo por parte de la mayoría de los encuestados. Menos del diez por ciento de los participantes del estudio consideró el uso de condones en general y durante el embarazo como algo muy fácil de hacer.

\section{TABLA 2. PORCENTAJE DE ENCUESTADOS QUE PERCIBEN EL SIGUIENTE COMPORTAMIENTO PREVENTIVO COMO "MUY FÁCIL"}

\begin{tabular}{l|c}
\hline COMPORTAMIENTO & $\%$ \\
\hline Cambiar agua almacenada intencionalmente & $28 \%$ \\
\hline Usar larvicida & $27 \%$ \\
\hline Vaciar agua estancada en lugares comunes & $26 \%$ \\
\hline Limpiar recipientes de agua & $25 \%$ \\
\hline Tapar recipientes de agua & $25 \%$ \\
\hline Usar repelente & $25 \%$ \\
\hline Vaciar agua estancada en la comunidad & $23 \%$ \\
\hline Usar condones en general & $6 \%$ \\
\hline Usar condones durante el embarazo & $6 \%$ \\
\hline
\end{tabular}

\section{Percepciones de efectividad de conductas preventivas}

Al enumerar conductas preventivas según su nivel de efectividad para prevenir la crianza de mosquitos y enfermedades como el Zika, casi dos tercios de los participantes consideró que despejar basura afuera del hogar era el método más efectivo, seguido por eliminar agua estancada (49 por ciento) y limpiar recipientes de agua (41 por ciento) (ver Tabla 3).

La diferencia entre hombres y mujeres fue significativa: menos mujeres identificaron el uso de larvicida (11 por ciento frente a un 21 por ciento de los hombres, $p<0.05$ ) o cambiar agua almacenada (16 por ciento frente a un 24 por ciento de los hombres, $p<0.01$ ) como uno de los tres comportamientos preventivos más efectivos. 


\section{Hallazgos clave sobre comportamientos preventivos}

\section{Prácticas para prevenir la transmisión sexual del Zika}

Si bien 15 por ciento de los encuestados utilizó condones durante algún encuentro sexual en los últimos treinta días, menos del uno por ciento respondió haberlos usado para prevenir el Zika.

\section{TABLA 3. PORCENTAJE DE ENCUESTADOS QUE PERCIBEN EL SIGUIENTE COMPORTAMIENTO COMO UNA DE LAS TRES FORMAS MÁS EFECTIVAS PARA PREVENIR EL ZIKA}

\begin{tabular}{l|c}
\hline COMPORTAMIENTO & $\%$ \\
\hline Despejar basura afuera de la casa & $62 \%$ \\
\hline Eliminar agua estancada & $49 \%$ \\
\hline Limpiar recipientes de agua & $41 \%$ \\
\hline Fumigar con insecticida (ej. Raid) & $24 \%$ \\
\hline Cambiar agua almacenada & $20 \%$ \\
\hline Usar repelente & $17 \%$ \\
\hline Usar larvicida & $16 \%$ \\
\hline Tapar contenedores o recipientes de agua & $9 \%$ \\
\hline Usar espirales repelentes & $9 \%$ \\
\hline Usar condones & $6 \%$ \\
\hline Usar mosquiteros en las camas & $4 \%$ \\
\hline Usar rejillas en ventanas y puertas & $9 \%$ \\
\hline
\end{tabular}

\section{Prácticas para prevenir picaduras de mosquitos y criaderos de mosquitos}

De las personas encuestadas:

- 78 por ciento respondió haber hecho algo para prevenir picaduras de mosquito en los últimos treinta días, pero solo 71 por ciento declara haber llevado a cabo al menos una práctica preventiva de alta efectividad en ese tiempo.

- 64 por ciento respondió haber hecho algo para prevenir picaduras de mosquito en los últimos siete días, pero solo 58 por ciento declara haber llevado a cabo al menos una práctica preventiva de alta efectividad en ese tiempo.
Según las respuestas a una pregunta abierta, la Figura 2 muestra los comportamientos preventivos más frecuentes realizados en los últimos 30 días y últimos 7 días. El más reportado fue despejar basura en el entorno de la vivienda, mientras que el menos frecuente fue usar ropa de manga larga. Los comportamientos preventivos de mayor efectividad están marcados con un asterisco.

Casi un cuarto (22 por ciento) de las personas encuestadas respondió no haber llevado a cabo ningún tipo de conducta preventiva en los últimos 30 días. Estar muy ocupado (23 por ciento) y no estar preocupado por las picaduras de mosquito (13 por ciento) fueron los motivos más mencionados por los participantes para explicar la baja cantidad de conductas preventivas realizadas.

Respecto al uso de repelente, la barrera más común para su uso fue su costo (34 por ciento) y falta de materiales ( 22 por ciento).

\section{FIGURA 2. COMPORTAMIENTOS PREVENTIVOS EN LOS ÚLTIMOS 30 Y 7 DÍAS}

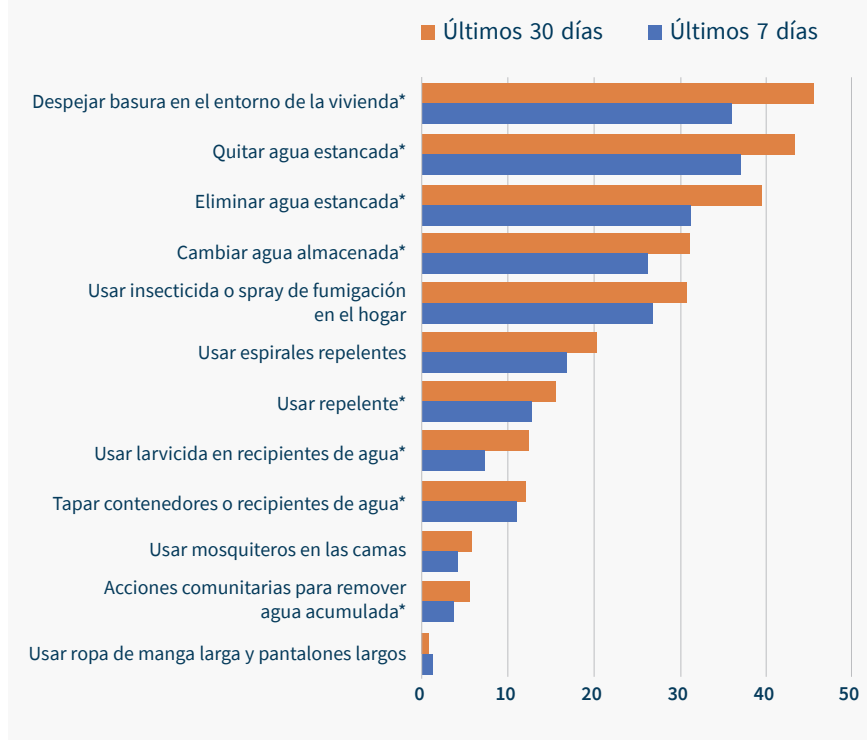

\section{Prácticas relacionadas con recipientes de agua}

Para entender la manera en que las personas en Honduras limpian sus recipientes o contenedores de agua, se les pidió a quienes lo habían hecho en los últimos siete días que especificaran cada paso que llevaron a cabo. La Tabla 4 muestra las acciones reportadas para limpiar recipientes de agua. Más de un tercio de quienes respondieron a esta pregunta (40 por ciento) reportaron haber aplicado detergente a las paredes del recipiente, pero solo un 24 por ciento le aplicaron cloro. Aproximadamente un cuarto de las personas le agregó cloro al agua (25 por ciento), un método de baja efectividad para eliminar mosquitos o larvas de mosquito. Aun menos 
encuestados respondieron haber cepillado el recipiente (18 por ciento), enjuagado el recipiente (17 por ciento) y vaciado el recipiente (16 por ciento) como pasos para limpiarlo. Solo 11 por ciento de los participantes respondió haber esperado algunos minutos para dejar actuar los productos de limpieza en la superficie del recipiente de agua.

Además de la encuesta, también se recogieron datos mediante la observación de recipientes o contenedores de agua en las casas de los participantes. 456 de los 609 encuestados en Honduras (75 por ciento) accedió a que un encuestador observara los recipientes o contenedores de agua de su hogar.

\section{TABLA 4. PORCENTAJE DE ENCUESTADOS QUE LIMPIARON SU RECIPIENTE O CONTENEDOR DE AGUA CON LA SIGUIENTE ACCIÓN}

\begin{tabular}{l|c}
\hline ACCIONES & $\%$ \\
\hline Aplicar detergente a las paredes del recipiente & $40 \%$ \\
\hline Aplicar cloro al agua & $25 \%$ \\
\hline Aplicar cloro a las paredes del recipiente & $24 \%$ \\
\hline Cepillar el recipiente & $18 \%$ \\
\hline Enjuagar el recipiente & $17 \%$ \\
\hline Vaciar el recipiente & $16 \%$ \\
\hline $\begin{array}{l}\text { Dejar que los productors de limpieza hagan } \\
\text { efecto durante algunos minutos }\end{array}$ & $11 \%$ \\
\hline
\end{tabular}

Del total, 480 de los contenedores observados fueron pilas y 117 fueron recipientes de agua de largo plazo. Los encuestadores observaron las tapas de los recipientes para evaluar su calidad. Para tapar un recipiente de manera efectiva, las tapas deben cubrir completamente el recipiente y encajar bien, evitando cualquier espacio abierto en toda la circunferencia; si el material de la tapa es plástico sólido, no debe estar doblado ni debe permitir que el agua se acumule en su superficie; si el material de la tapa es maleable, no debe tocar la superficie del agua para no arriesgar la formación de criaderos de mosquitos adicionales.

En total, se hallaron larvas de mosquito en 10 por ciento de las pilas y 18 por ciento de los recipientes o contenedores de largo plazo. No se encontraron diferencias significativas entre las pilas que estaban tapadas de manera correcta y las que no. En contraste, era significativamente menos probable que recipientes de largo plazo que estaban tapados de manera correcta tuvieran larvas de mosquito, frente a aquellos tapados de manera incorrecta (recipientes que no estaban cubiertos o cuya tapa no cumplía con criterios de eficiente cobertura). Se hallaron larvas en solo dos por ciento de los recipientes de largo plazo cubiertos de manera correcta, frente a un 24 por ciento entre recipientes tapados de manera incorrecta $(p<0.03)$. Esta diferencia se mantiene incluso al controlar por el autorreporte de limpieza de los recipientes en los últimos treinta días (ver Tabla 5).

\section{TABLA 5. RECIPIENTES DE LARGO PLAZO CON LARVAS DE MOSQUITO}

\begin{tabular}{l|c} 
ACCIONES & $\%$ \\
\hline Tapados de manera correcta & $\mathbf{2 \%}$ \\
\hline Tapados de manera incorrecta & $\mathbf{2 4 \%}$
\end{tabular}

\section{Asociaciones entre determinantes de comportamiento y comportamientos preventivos $\S$}

En Honduras, el principal predictor para realizar comportamientos que prevengan la picadura y reproducción de mosquitos es tener conocimiento sobre comportamientos preventivos efectivos. Individuos con un buen conocimiento del Zika -que conocían ocho o más comportamientos preventivos- tenían 40 por ciento mayor de probabilidad de realizar comportamientos preventivos que aquellos que no. Un mayor conocimiento de comportamientos preventivos efectivos estaba relacionado significativamente con un mayor autorreporte de los siguientes comportamientos: tapar recipientes de agua $(p<0.001)$, limpiar agua estancada $(p<0.001)$, y limpiar recipientes de agua $(p<0.001)$. Adicionalmente, estar informado de que tapar recipientes o contenedores de agua previene la reproducción de mosquitos es el único factor correlacionado significativamente con haber tapado recipientes de agua en los últimos 30 días.

Controlando por nivel de conocimiento, era 12 por ciento más probable que personas que recibieron visitas al hogar por parte de voluntarios o técnicos para hablar de prevención hayan eliminado agua estancada y limpiado recipientes de agua en los últimos treinta días ( $p=0.01$ y $p=0.006$, respectivamente), que personas que no recibieron a alguien para hablar de prevención.

La efectividad percibida de un comportamiento preventivo está significativamente relacionada con su realización. Las personas que consideraron eliminar agua estancada como un comportamiento preventivo efectivo tenían un 10 por ciento mayor de probabilidad de haber hecho dicha acción ( $p=0.02$ ). Asimismo, las personas que percibieron el uso de repelentes

$\S$ Los resultados de esta sección están basados en análisis de regresión logística. 
como un comportamiento preventivo efectivo tenían un 24 por ciento mayor de probabilidad de haberlos usados $(p<0.001)$.

\section{Conclusiones e implicancias para el futuro}

En las áreas de Honduras que fueron estudiadas, la gran mayoría de la población ha escuchado acera del virus del Zika, y casi todos quienes conocen el virus saben que se transmite mediante mosquitos. Casi dos tercios de las personas que saben de que el Zika se transmite mediante mosquitos están informadas que las picaduras pueden ocurrir a cualquier hora del día o la noche. No obstante, pocas personas son conscientes de que el virus se puede transmitir mediante relaciones sexuales, y los hombres saben menos que las mujeres sobre los efectos adversos sobre la salud que puede generar el Zika durante el embarazo. Si bien se estima que solo entre cuatro y cinco por ciento de las transmisiones de Zika ocurren mediante relaciones sexuales, las implicancias de la transmisión del Zika durante el embarazo son tan graves que los programas deben continuar educando sobre la transmisión sexual del Zika como también sobre sus posibles consecuencias durante el embarazo, especialmente entre mujeres embarazadas y sus parejas. 5,6

Existe un alto nivel de conocimiento de comportamientos preventivos de control de vector, que son efectivos en prevenir reproducción de mosquitos y propagación del Zika (la única excepción es tapar recipientes de agua, una práctica poco conocida por las personas encuestadas). Sin embargo, pocas personas saben acerca de prácticas de protección personal, como el uso de repelentes o el uso de condones. Las personas casi no saben que el condón se puede usar para prevenir el Zika. Además, comportamientos preventivos efectivos, como tapar recipientes de agua y el uso de repelentes sobre la piel, eran prácticas menos frecuentes que comportamientos de menor efectividad (como el uso de espirales repelentes o spray de fumigación).

Los programas deben continuar priorizando actividades que eduquen sobre conductas de protección personal ante el Zika, que son particularmente importantes durante el embarazo. Asimismo, los mensajes deben incluir instrucciones detalladas que expliquen los comportamientos de mayor complejidad. ${ }^{7,8}$ Para que comportamientos preventivos de control de vector (como limpiar recipientes de agua o tapar recipientes de manera correcta) sean efectivos en eliminar mosquitos, es de suma importancia no saltarse ningún paso.

Finalmente, las visitas presenciales a los hogares siguen siendo un mecanismo favorable para estimular e informar a poblaciones en situaciones de alto riesgo y promover prácticas preventivas. Los especialistas que visiten hogares pueden destacar con mayor énfasis los comportamientos preventivos de protección personal, para que lleguen a ser igualmente conocidos que los comportamientos preventivos de control vector. 


\section{Referencias bibliográficas}

1 World Health Organization (WHO). 2016. Zika Strategic Response Plan. Geneva, Switzerland: WHO.

2 Haby, Michelle M. et al. 2018. "Prevalence of asymptomatic Zika virus infection: a systematic review," Bulletin of the World Health Organization 96: 402-413D.

3 Centers for Disease Control and Prevention (CDC). 2018. Congenital Zika Syndrome \& Other Birth Defects. Atlanta: CDC. Available from www.cdc.gov/pregnancy/ zika/testing-follow-up/zika-syndrome-birth-defects. html.

4 Health Communication Capacity Collaborative. 2016. Social and Behavior Change Communication for Emergency Preparedness Implementation Kit Baltimore: Johns Hopkins University (JHU). Available from: http://healthcommcapacity.org/wp-content/ uploads/2017/01/SBCCforEP 1-Kit.pdf.

5 Coelho, Flavio Codeco et al. 2016. "Higher incidence of Zika in adult women than adult men in Rio de Janeiro suggests a significant contribution of sexual transmission from men to women," International Journal of Infectious Diseases 51: 128-132.

6 Rao, Rashmi et al. 2017. "Zika risk and pregnancy in clinical practice: ongoing experience as the outbreak evolves," Obstetrics and Gynecology 129(6): 10981103

7 Breakthrough ACTION+RESEARCH. 2018. Zika Prevention Behavior Matrix. Baltimore: JHU. Available from www.zikacommunicationnetwork.org/resources/ zika-prevention-behavior-matrix.

8 Breakthrough ACTION+RESEARCH. 2018. Technical Specification Content Guide for Behaviors With a High Potential to Prevent Zika. Baltimore: JHU. Available from www.zikacommunicationnetwork.org/resources/ technical-specifications-content-guide-behaviors-highpotential-prevent-zika.

\section{Agradecimientos}

Este informe de investigación describe el trabajo liderado por la Universidad de Tulane bajo el Proyecto Breakthrough RESEARCH, en colaboración con TEPHINET en Honduras. Este informe fue desarroIlado por Martha Silva y Julia Fleckman de la Universidad de Tulane, junto a Kate Spielman del Population Council. Paul Hewett del Population Council y Arianna Serino de la Agencia para el Desarrollo Internacional de los Estados Unidos (The United States Agency for International Development - USAID) sirvieron de revisores técnicos. Heidi Worley de PRB apoyó el trabajo editorial y Katie Hoch realizó el diseño gráfico. Cristián Valenzuela tradujo el texto al español.

\section{Cita sugerida:}

Breakthrough RESEARCH. 2019. "Conocimiento, Actitudes y Prácticas sobre el Zika: Implicancias Prográmaticas para Prevención del Zika en la Honduras," Programmatic Research Brief. Washington, DC: Population Council.

\section{Crédito fotográfico}

MarcPo, Getty Images

(C) 2019 The Population Council. Todos los derechos reservados.

\section{Breakthrough RESEARCH, Population Council}

4301 Connecticut Ave., NW, Suite 280 | Washington, DC 20008 +12022379400 | breakthroughactionandresearch.org

BreakthroughRESEARCH@popcouncil.org

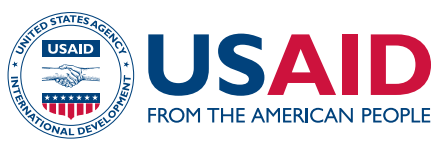

Breakthrough RESEARCH is made possible by the generous support of the American people through the United States Agency for International Development (USAID) under the terms of cooperative agreement no. AIDOAA-A-17-00018. The contents of this document are the sole responsibility of the Breakthrough RESEARCH and Population Council and do not necessarily reflect the views of USAID or the United States Government.

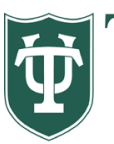

Tulane University

POPULATION COUNCIL

Ideas. Evidence. Impact.

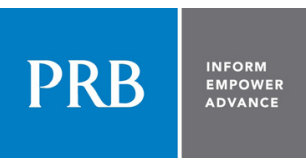

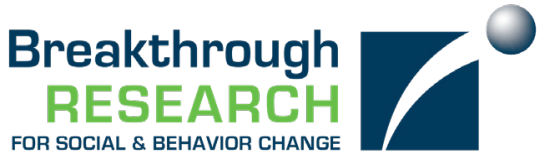

Breakthrough RESEARCH catalyzes social and behavior change (SBC) by conducting state-ofthe-art research and evaluation and promoting evidence-based solutions to improve health and development programs around the world. Breakthrough RESEARCH is a consortium led by the Population Council in partnership with Avenir Health, ideas42, Institute for Reproductive Health at Georgetown University, Population Reference Bureau, and Tulane University. 